\title{
Pengaruh Tingkat Bunga terhadap Penentuan Harga Suatu Kontrak Opsi pada Model Black-Scholes
}

\author{
Riaman $^{1}$, Betty Subartini' ${ }^{2}$, F. Sukono ${ }^{3}$ \\ 1,2,3)Departemen Matematika, Fakultas MIPA, Universitas Padjadjaran, Bandung \\ Jl. Raya Bandung Sumedang KM 21 Jatinangor Sumedang 45363 \\ Email: riaman@unpad.ac.id, betty.subartini@unpad.ac.id, sukono@unpad.ac.id
}

\begin{abstract}
ABSTRAK
Kegiatan investasi akhir-akhir ini berkembang pesat. Investasi yang populer saat ini antara lain adalah investasi tanah, investasi emas, dan investasi saham. Selain Investasi saham di pasar modal, terdapat investasi opsi saham di pasar derivatif. Opsi merupakan salah satu bentuk sekuritas derivatif. Pada dasarnya opsi merupakan hak untuk melakukan sesuatu dan tidak berkewajiban untuk melakukannya. Di dalam menentukan harga opsi, tingkat bunga, volatilitas, dan faktor lain berpengaruh. Pada paper ini, akan dibahas bagaimana dan berapa besar pengaruh tingkat bunga terhadap harga suatu kontrak opsi. Model yang digunakan adalah model Black-Scholes. Dengan menggunakan model Black-Scholes, akan ditentukan harga opsi beli dan opsi jual serta akan ditunjukkan bahwa semakin tinggi tingkat bunga maka semakin tinggi harga opsi beli dan semakin rendah harga opsi jual dan sebaliknya.
\end{abstract}

Kata kunci: Harga Opsi, model Black-Scholes, Opsi, Tingkat Bunga.

\begin{abstract}
Nowadays, Investment grow rapidly. Many people invest in land, jewelry, and stocks sectors. Aside from that, there is newer investment called options in derivative security. In short, options holder have a right to exercise his contract but not an obligation. To determine options price, some factors must take in to account, such as interest rate, volatility, etc. In this paper, we will show how and how much interest rates affect in options price. The model that will be used is Black-Scholes Options Pricing Model. We will show how much call options and put options price, also we will show that interest rates have positive correlations with call options but negative ones with put option. That is if the interest rates increase, call options price will increase too, but put options price will decrease.
\end{abstract}

Keywords: Black-Scholes Option Pricing Model, Interest Rates, Options, Options Price.

\section{Pendahuluan}

Akhir-akhir ini, investasi mulai ramai digemari. Investasi yang populer saat ini di antaranya adalah investasi tanah, investasi emas, dan investasi saham. Investasi saham merupakan kegiatan investasi dengan nilai risiko yang sulit untuk ditebak, karena itulah investasi saham banyak diminati. Selain investasi saham, terdapat investasi sekuritas derivatif. "Sekuritas derivatif (derivative security) adalah sekuritas yang nilainya tergantung sepenuhnya pada atau diturunkan (disesuaikan) dengan nilai dari asset yang lain" [1]. Hal ini berarti sekuritas derivatif ada jika terdapat sekuritas utama yang dijadikan turunannya. Salah satu sekuritas derivatif adalah opsi saham. Akan tetapi perdagangan opsi saham di Indonesia masih sangat kurang diminati, padahal jiga diteliti, opsi saham memiliki keuntungan yang sangat tinggi namun dengan risiko yang sangat rendah. Opsi dapat mengurangi dampak risiko dengan melakukan hedging (lindung nilai), artinya selain dapat membeli atau menjual opsi, investor juga dapat membeli saham dari opsi tersebut [3].

Menentukan harga opsi tidaklah mudah. Terdapat beberapa cara untuk menentukan harga suatu kontrak opsi, di antaranya Binomial Option Pricing Model (BOPM), model Black-Scholes, Simulasi Monte-Carlo, dan sebagainya [1]. Pada paper ini, akan dibahas perhitungan secara analitis untuk 
menentukan prakiraan harga opsi, yaitu dengan menggunakan model Black-Scholes. Di dalam model Black-Scholes, salah satu variabel yang menentukan adalah tingkat suku bunga. Pada umumnya tingkat suku bunga ditentukan oleh pemerintah. Hal tersebut dilakukan guna menjaga kestabilan perekonomian negara. Namun pada paper ini, akan diteliti bagaimana dan sebesar apa pengaruh tingkat bunga terhadap harga opsi tersebut. Karena di dalam pasar modal, tingkat bunga tidaklah konstan dan cenderung berubah tiap saat [4].

\section{Metode Penelitian}

\subsection{Opsi, Tingkat Bunga, dan Volatilitas}

"Opsi adalah salah satu jenis kontrak masa depan (future contract) di mana jenis kontraknya didasarkan pada ide pentransferan kepemilikan terhadap suatu asset di masa depan pada harga yang telah disepakati” [1]. Opsi merupakan salah satu bentuk sekuritas derivatif (derivative security). Pada dasarnya opsi merupakan hak untuk melakukan sesuatu dan tidak berkewajiban untuk melakukannya. Artinya, pemilik opsi memiliki hak untuk menggunakan haknya apabila pemilik opsi tersebut berpikir bahwa yang dilakukannya itu menguntungkan, sebaliknya apabila tidak menguntungkan, pemilik opsi tidak berkewajiban untuk menggunakan haknya. Terdapat dua jenis opsi, yaitu opsi beli (call option) dan opsi jual (put option).

Dalam menentukan harga opsi, tingkat bunga dan volatilitas memiliki pengaruh yang cukup signifikan. "Suku Bunga dalam ekonomi ditentukan oleh keseimbangan dalam permintaan dan penawaran uang" [5]. Suku Bunga adalah biaya atas peminjaman uang. Suku Bunga biasanya berupa persentase dari besarnya pinjaman yang dilakukan. Biaya tersebut digunakan untuk menghitung besarnya keuntungan yang diperoleh oleh pihak yang meminjamkan. Sedangkan Volatilitas merupakan variabel penting dalam menentukan harga suatu opsi. Volatilitas dapat diukur dengan mencari standar deviasi atau variansi antara keuntungan sekuritas yang sama. Pada umumnya, semakin besar volatilitas maka semakin besar pula risiko yang dimiliki oleh sekuritas tersebut. Volatilitas cenderung berubah setiap waktu, baik naik maupun turun. Menurut statistika, volatilitas berarti penyimpangan standar tahunan dalam hal harga harian di pasar acuan. Volatilitas terbagi atas dua jenis, yaitu volatilitas historis dan volatilitas tak langsung. Volitlitas historis diperoleh dengan cara mengambil rata-rata perubahan di pasar sebelumnya [2]. Peluang atau lebih dikenal dengan Probabilitas merupakan suatu cara untuk mengungkapkan kepercayaan bahwa suatu kejadian akan terjadi atau telah terjadi. Peluang suatu kejadian adalah angka yang menunjukkan kemungkinan terjadinya suatu kejadian. Nilai dari peluang, yaitu di antara 0 dan 1 . Peluang biasanya berkaitan dengan peubah acak. Peubah acak digunakan untuk mengekspresikan bagaimana peluang suatu kejadian [3].

\subsection{Model Black-Scholes}

Model Black-Scholes dikembangkan oleh Fisher Black dan Myron Scholes pada tahun 1973. Model Black-Scholes digunakan untuk opsi Saham Eropa. Di dalam model Black-Scholes, terdapat beberapa asumsi di antaranya tidak ada dividen, tidak ada biaya administrasi, suku bunga bebas risiko dan konstan selama umur opsi. Di dalam menentukan harga opsi, dapat menggunakan model Black-Scholes [4], yaitu:

di mana:

$$
C(s, t)=N\left(\omega d_{1}\right) \omega S-N\left(\omega d_{2}\right) \omega K e^{-r(T-t)}
$$

$C(S, t)$ : harga opsi

$\omega=1$ untuk opsi beli dan $\omega=-1$ untuk opsi jual

Model untuk harga opsi beli, yaitu:

$C(S, t)=N\left(d_{1}\right) S-N\left(d_{2}\right) K e^{-r(T-t)}$

Sedangkan model untuk opsi jual yaitu: 


$$
P(S, t)=K e^{-r(T-t)}-S+C(S, t)=N\left(-d_{2}\right) K e^{-r(T-t)}-N\left(-d_{1}\right) S
$$

di mana:

$$
d_{1}=\frac{\ln \left(\frac{S}{K}\right)+\left(r+\frac{1}{2} \sigma^{2}\right)(T-t)}{\sigma \sqrt{T-t}}
$$

$d_{2}=d_{1}-\sigma \sqrt{T-t}$

$C(S, t): \quad$ harga opsi beli

$P(S, t): \quad$ harga opsi jual

$S: \quad$ harga saham

$K$ : $\quad$ harga kesepakatan

$r$ : $\quad$ tingkat suku bunga bebas risiko

T: $\quad$ waktu tersisa hingga jatuh tempo (dalam tahun)

$\sigma: \quad$ volatilitas dari return harga saham

Jenis Penelitian yang dilakukan adalah studi literatur mengenai opsi saham dan dilanjutkan dengan studi kasus terhadap harga Opsi Eropa yang sahamnya terdapat di dalam kumpulan saham unggulan indeks LQ45. Studi kasus dilakukan dengan menyimulasikan data saham yang didapat untuk menaksir harga opsi yang sesuai. Data yang diambil merupakan data saham penutupan PT. Telekomunikasi Indonesia Tbk.

Langkah-langkah yang dilakukan untuk menentukan harga opsi, yaitu:

Mencari dan menentukan data historis

Menentukan variabel yang diperlukan yaitu S (harga saham penutupan), K (harga kesepakatan/exercise antara penjual dan pembeli opsi), $\mathrm{r}$ (tingkat bunga bebas risiko), $\mathrm{T}$ (waktu tersisa hingga jatuh tempo dalam tahun), (volatilitas dari return harga saham).

Menentukan harga opsi beli dan opsi jual dengan menggunakan model Black-Scholes.

\section{Hasil dan Pembahasan}

Data Penelitian yang digunakan pada penelitian ini adalah data historis saham peringkat 41 saham unggulan yang tergabung di dalam indeks LQ45 periode Februari-Juli 2016. Saham peringkat 41 dari indeks LQ45 periode Februari-Juli 2016, yaitu saham PT. Telekomunikasi Indonesia Tbk (TLKM) [6].

\subsection{Variabel-Variabel Penentu Harga Opsi}

Variabel yang digunakan untuk menghitung harga opsi tipe Eropa meliputi S (harga saham penutupan), K (harga kesepakatan/exercise antara penjual dan pembeli opsi), r (tingkat bunga bebas risiko), $\mathrm{T}$ (waktu tersisa hingga jatuh tempo dalam tahun), $\sigma$ (volatilitas dari return harga saham). Nilai dari S dapat dilihat pada data historis penutupan harga saham PT. Telekomunikasi Indonesia Tbk. Pada tanggal 29 Maret 2016, harga saham penutupan PT. Telekomunikasi Indonesia Tbk sebesar Rp3.300,00. Waktu jatuh tempo ditentukan selama 6 bulan, sedangkan suku bunga bebas risiko sebesar 6,75\%. Harga kesepakatan/exercise antara penjual dan pembeli opsi ditentukan sebesar Rp3.400,00. Nilai volatilitas

$(\sigma)$ dapat ditentukan dengan langkah-langkah sebagai berikut:

1. Menentukan nilai Return Saham

$$
R_{t}=\ln \left(\frac{s_{t}}{s_{t-1}}\right)
$$

2. Menentukan nilai ekspektasi

$$
E\left[R_{t}\right]=\frac{1}{n} \sum_{t=1}^{n} R_{t}
$$

3. Menentukan nilai variansi

$$
\operatorname{Var}=\sum_{t=1}^{n} \frac{\left[\left(R_{t}-E\left(R_{t}\right)\right)^{2}\right]}{n}
$$

4. Menentukan nilai volatilitas

$$
\sigma=\sqrt{\operatorname{Var}}
$$

Pertama, akan dicari nilai return untuk $t=2$ (nilai return untuk $t=1$ diasumsikan bernilai 0 ), dengan menggunakan Persamaan (6) diperoleh: 


$$
R_{2}=\ln \left(\frac{S_{2}}{S_{1}}\right)=\ln \left(\frac{2825}{2835}\right)=-0.003533573
$$

Kedua, akan dicari nilai dari $E\left[R_{t}\right]$ dengan menggunakan Persamaan (7) :

$$
E\left[R_{t}\right]=\frac{1}{n} \sum_{t=1}^{n} R_{t}=0.000656081
$$

Ketiga, akan dihitung nilai dari variansi dengan menggunakan Persamaan (8), diperoleh:

$$
\operatorname{Var}=\sum_{t=1}^{n} \frac{\left[\left(R_{t}-E\left(R_{t}\right)\right)^{2}\right]}{n}=0.000271476
$$

Terakhir, akan dihitung nilai dari volatilitas saham penutupan PT. Telekomunikasi Indonesia Tbk dengan menggunakan Persamaan (9)

$$
\sigma=\sqrt{\operatorname{Var}}=\sqrt{0.000271476}=0.016476529
$$

Dapat dilihat bahwa besar volatilitas saham PT. Telekomunikasi Indonesia Tbk sebesar 0,0165 atau $1,65 \%$.

\subsection{Penentuan Harga Opsi dengan Model Black-Scholes}

Model Black-Scholes adalah model matematika dalam bidang finansial. Berdasarkan model BlackScholes, dapat ditentukan secara analitis prakiraan harga Opsi Eropa. Secara manual, perhitungan harga opsi beli dan opsi jual dengan menggunakan metode Black-Scholes dapat dilakukan sebagai berikut:

Menentukan nilai $d_{1}$ dengan menggunakan persamaan (4):

$$
\begin{aligned}
d_{1} & =\frac{\ln (S / K)+\left(r+\frac{1}{2} \sigma^{2}\right) T}{\sigma \sqrt{T}} \\
& =\frac{\ln (3.300 / 3.400)+\left(0,0675+\frac{1}{2} 0.000271476\right)(0.5)}{0.016476529 \sqrt{0.5}} \\
& =0.340315829
\end{aligned}
$$

Menentukan nilai $d_{2}$ dengan menggunakan Persamaan (5):

$$
\begin{aligned}
d_{2} & =d_{1}-\sigma \sqrt{T} \\
& =0.340315829-0.016476529 \sqrt{0.5} \\
& =0.340315829-0.011650665 \\
& =0.328665163
\end{aligned}
$$

Setelah menentukan nilai dari $d_{1}$ dan $d_{2}$, dapat dihitung prakiraan harga opsi beli dengan menggunakan Persamaan (3):

$$
\begin{aligned}
C(S, t) & =N\left(d_{1}\right) S-N\left(d_{2}\right) K e^{-r T} \\
& =N(0.34031583) 3.300-N(0.32866516) 3.400 e^{-0,0675(0.5)} \\
& =0.633190651(3.300)-0.628795606\left(3.400 e^{-0.03375}\right) \\
& =2089.529148-2066.954784 \\
& =R p 22,57
\end{aligned}
$$

Sedangkan dengan menggunakan persamaan ( 2.7 ) dapat dihitung prakiraan harga opsi beli, yaitu:

$$
\begin{aligned}
P(S, t) \quad & N\left(-d_{2}\right) K e^{-r T}-N\left(-d_{1}\right) S \\
& =N(-0.32866516) 3.400 e^{-0,0675(0.5)}-N(-0.34031583) 3.300 \\
& =0.371204394\left(3.400 e^{-0,0675(0.5)}\right)-0.366809349(3.300) \\
& =1220.21002-1210.470852 \\
& =
\end{aligned}
$$

Perhitungan tersebut didasarkan pada tingkat bunga yang ditentukan oleh Bank Indonesia saat ini. Namun bagaimana untuk hasil tingkat bunga yang berbeda, dengan mengasumsikan bahwa tingkat bunga tidak sama dengan tingkat bunga yang dikeluarkan oleh Bank Indonesia yaitu misalkan dengan tingkat bunga 6,5\%, maka perhitungan diperoleh sebagai berikut:

$$
\begin{aligned}
d_{1} & =\frac{\ln (S / K)+\left(r+\frac{1}{2} \sigma^{2}\right) T}{\sigma \sqrt{T}} \\
& =\frac{\ln (3.300 / 3.400)+\left(0,065+\frac{1}{2} 0.000271476\right)(0.5)}{0.016476529 \sqrt{0.5}}
\end{aligned}
$$




$$
\begin{aligned}
& =\frac{\ln (0.970588235)+(0,065+0.03645)(0.5)}{0.016476529 \sqrt{0.5}} \\
& 0.016476529 \sqrt{0.5} \\
& =\frac{-0.029852963+(0.065135738)(0.5)}{0.016476529 \sqrt{0.5}} \\
& 0.016476529 \sqrt{0.5} \\
& =\frac{-0.029852963+0.032567869}{0.016476529 \sqrt{0.5}} \\
& =0.002714906 \\
& \overline{0.011650665} \\
& =\quad 0.233025819 \\
& d_{2}=d_{1}-\sigma \sqrt{T} \\
& =0.233025819-0.016476529 \sqrt{0.5} \\
& =0.233025819-0.011650665 \\
& =0.221375154 \\
& =N(0.233025819) 3.300-N(0.22137515) 3.400 e^{-0,065(0.5)} \\
& =0.592129322(3.300)-0.587599832\left(3.400 e^{-0.0325}\right) \\
& =1954.026762-1933.953417 \\
& =\quad R p 20,07 \\
& P(S, t)=N\left(-d_{2}\right) K e^{-r T}-N\left(-d_{1}\right) S \\
& =N(-0.22137515) 3.400 e^{-0,065(0.5)}-N(-0.233025819) 3.300 \\
& =0.412400168\left(3.400 e^{-0.0325}\right)-0.407870678(3.300) \\
& =1357.322912-1345.973238 \\
& =\quad R p 11,35
\end{aligned}
$$

\begin{tabular}{|c|c|c|c|c|c|}
\hline Parameter & $r=6,50 \%$ & $r=7,50 \%$ & $r=7,25 \%$ & $r=6,25 \%$ & $r=7,00 \%$ \\
\hline Harga Saham & & & Rp 3.300,00 & & \\
\hline Harga Ecercise & & & Rp $3.400,00$ & & \\
\hline Waktu jatuh tempo & & & 6 bulan & & \\
\hline Volatilitas & & & $1,65 \%$ & & \\
\hline $\begin{array}{ll}\text { Prakiraan } & \text { Harga } \\
\text { Opsi Beli } & \\
\end{array}$ & Rp 20,07 & Rp 31,03 & Rp 28,06 & Rp 17,74 & Rp 25,24 \\
\hline $\begin{array}{l}\text { Prakiraan } \\
\text { Opsi Jual }\end{array}$ & $\operatorname{Rp~11,35~}$ & Rp 5,89 & $\operatorname{Rp} 7,02$ & $\operatorname{Rp} 13,13$ & Rp 8,30 \\
\hline
\end{tabular}

Sehingga untuk tingkat bunga yang berbeda akan menghasilkan prakiraan harga opsi yang berbeda seperti pada Tabel 1 .

Tabel 1. Pengaruh tingkat bunga terhadap penentuan harga opsi

\section{Simpulan}

Menurut hasil pembahasan yang telah diuraikan, dengan menggunakan model Black-Scholes, diperoleh suatu hasil prakiraan harga opsi beli maupun opsi jual secara analitis, dengan waktu jatuh tempo yang sama dan volatilitas yang sama serta harga saham dan harga exercise yang sama, semakin tinggi tingkat bunga maka semakin rendah prakiraan harga kontrak opsi beli, dan sebaliknya untuk kontrak opsi jual, semakin tinggi tingkat bunga semakin rendah prakiraan harga kontrak opsi jual.

\section{Daftar Pustaka}

1. Baxter, M., and Rennie, A. 1996. Financial Calculus an Introduction to Derivative Pricing. Cambridge: Cambridge University Press. 
2. Brennan, M. J., and Schwartz, E. S. 1976. The pricing of equity-linked life insurance policy with an asset value guarantee. Journal of Financial Economics, 3, 195-213.

3. Black, F. and Scholes, M. 1973. The Pricing of Options and Corporate Liabilities. The Journal of Political Economy, Vol. 81, No. 3, 637-654. The University of Chicago Press.

4. Chriss, N. A. 1997. Black-Scholes and Beyond, Option Pricing Models. United States of America: McGraw-Hill.

5. Capinski, M., and Zastawniak, T. 2003. Mathematics for Finance an Introduction to Financial Engineering. London: Springer.

6. Data historis saham peringkat 41 saham unggulan yang tergabung di dalam indeks LQ45 periode Februari-Juli 2016. Saham peringkat 41 dari indeks LQ45 periode Februari-Juli 2016, saham PT. Telekomunikasi Indonesia Tbk (TLKM). 